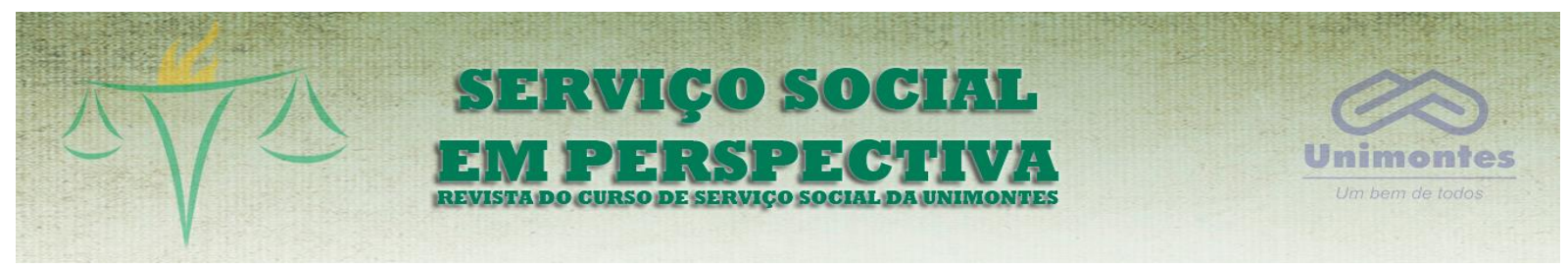

\title{
O ESTÁGIO SUPERVISIONADO EM SERVIÇO SOCIAL COMO ESTRATÉGIA DE FORTALECIMENTO DO PROJETO ÉTICO-POLÍTICO
}

\section{THE SUPERVISED INTERNSHIP IN SOCIAL WORK AS A STRATEGY FOR STRENGTHENING THE ETHICAL-POLITICAL PROJECT}

Resumo: O presente trabalho faz uma reflexão acerca do Projeto de Formação inscrito nas Diretrizes curriculares da ABEPSS e enfatiza a proposta de Estágio Supervisionado elucidado no referido projeto. Historicizamos e retomamos os principais documentos que normatizam e qualificam o significado do Estágio no âmbito do Serviço Social. Apontamos como esse processo ocorreu a partir da experiência docente com responsabilidades vinculadas diretamente ao Estágio. Por fim, apresentamos algumas das aproximações que foram possíveis a partir da socialização de uma atividade realizada na disciplina de Introdução ao Estágio que proporcionou reflexões e apreensões significativas para o fortalecimento da proposta de Estágio Supervisionado como estratégia do fortalecimento do Projeto éticopolítico.

Palavras-chave: Projeto de Formação; Estágio Supervisionado; Projeto éticopolítico.

\begin{abstract}
This paper reflects on the Training Project included in the ABEPSS curriculum guidelines and emphasizes the Supervised Internship proposal elucidated in the referred project. We historicize and retake the main documents that regulate and qualify the meaning of the Internship in the scope of Social Work. We pointed out how this process occurred from the teaching experience with responsibilities directly linked to the Internship. Finally, we present some of the approaches that were possible from the socialization of an activity carried out in the Introduction to Internship discipline that provided significant reflections and apprehensions for the strengthening of the Supervised Internship proposal as a strategy for strengthening the ethical-political Project.
\end{abstract}

Keywords: Training Project; Supervised internship; Ethical-political project.

\footnotetext{
${ }^{1}$ Assistente Socail . Mestranda do programa de Pós-graduação em Serviço Social da Universidade Federal de Juiz de Fora - UFJF. Graduada em Serviço Social pela Universidade Federal do Triângulo Mineiro - UFTM. Pesquisadora do Grupo de Estudo e Pesquisa em Fundamentos, Formação e Exercício Profissional em Serviço Social - GEFEPSS da UFTM Email: gabriele.ponciano@gmail.com
} 


\section{INTRODUÇÃO}

Partimos do pressuposto de que, as mudanças que ocorrem no bojo do Serviço Social, desde sua emergência, são históricas, ou seja, as determinações históricas, bem como as transformações societárias sejam elas de viés econômico, social, político e cultural, incidem na dinâmica da profissão.

Posto isso, ao considerarmos a conjuntura em que o Serviço Social brasileiro emerge é notório o cenário de acirramento das lutas sociais, dada a ausência histórica de intervenções integracionistas do Estado brasileiro, o final da década 1920, e, sobretudo no decorrer da década 1930 a "questão social" nacional exigia uma intervenção do Estado para além do seu trato repressivo e coercitivo.

É nesse contexto que o Serviço Social se desenvolve, e com vinculação direta com o Serviço Social franco-belga. Essa interlocução configurou, a principio, uma formação e intervenção calcada nos princípios tomistas e neotomistas, e a presença de um conservadorismo que é imanente ao seu desenvolvimento e institucionalização enquanto profissão. De modo que,

[...] o fundamento da instituição profissional era frequentemente deslocado para bases ético-morais, a legitimação prática fluía da intencionalidade do agente, e a validação teórica não possuía relevo ou não se registrava a simultaneidade destas duas dimensões (NETTO, 2011, p. 131).

Resgatar esses elementos é fundamental para apreendermos os saltos qualitativos que foram alcançados no interior da profissão, sobretudo, a partir do avanço da "intenção de ruptura" e aproximação com o marxismo e a tradição marxista. Tendo em vista que, o conservadorismo perpetrou historicamente 0 desenvolvimento da profissão no contexto brasileiro que em mais de 80 anos de Serviço Social é notória a abrangência de diversas matizes teóricas que recompõe tal conservadorismo no interior da profissão - com exceção da "intenção de ruptura" que acerca de 40 anos é hegemônica na profissão - destacam-se tendências vinculadas ao tomismo-netomismo; positivismo (funcionalismo-estruturalismo); fenomenologia, pós-modernidade (neoconservadorismo). 
É importante ponderar que, essas vertentes teóricas que são verificadas no Serviço Social, não incidem na profissão aleatoriamente, elas estão diretamente vinculadas com as mudanças na sociedade, e, sobretudo pelo ritmo nas lutas entre as classes sociais. Nessa direção, ao considerarmos o avanço da "intenção de ruptura" no bojo da profissão, esta tendência que encontra no marxismo e na tradição marxista subsídios para repensar o significado da profissão, bem como para romper com o seu conservadorismo imanente, surge em momento extremamente complexo da sociedade brasileira, em que vigorava regime ditatorial com fortes traços fascistas. Dado o cenário de arbítrio, de ataque às liberdades, de cerceamento ao pensamento crítico a intenção de ruptura só tem a possibilidade de alcançar maiores patamares na profissão no processo de transição democrática que inicia a partir de meados da década de 1970, mas se intensifica no curso da década 1980.

Um marco nesse processo é o $3^{\circ}$ Congresso Brasileiro de Assistentes Sociais (CBAS), que aconteceu em 1979, conhecido como Congresso da Virada é a partir desse espaço que a categoria profissional através das suas entidades representativas demonstrou publicamente seu compromisso com a classe trabalhadora e se reconhecendo como parte desta. Nas últimas décadas que seguiram a "Virada do Serviço Social" é notório a constituição de um legado crítico que comporta a ousadia e os esforços do conjunto da categoria na tarefa de ressignificação do Serviço Social.

Como reflexo desse permanente esforço coletivo da categoria, configurou-se um Projeto de Formação associado à perspectiva crítica que encontrou no marxismo e na tradição marxista subsídios para interpretar/apreender a realidade em uma perspectiva de totalidade considerando a relação dialética entre teoria e prática que perpassará todo o processo de formação e exercício profissional. Destacamos nesse processo a proposta de Estágio Supervisionado que constituí tal Projeto de Formação que condensa e reitera o compromisso atual do Serviço Social de apreender a realidade para transformá-la. 


\section{O ATUAL PROJETO DE FORMAÇÃo EM SERVIÇO SOCIAL E O ESTÁGIO SUPERVISIONADO}

As ressonâncias da teoria marxista, bem como da tradição marxista, no processo de constituição e consolidação do legado crítico da categoria podem ser identificadas já na proposta do currículo mínimo para a formação de 1982, no Código de Ética de 1986, e aperfeiçoado no Código de Ética de 1993, na Lei de Regulamentação da profissão (8662/1993) nas Diretrizes para a formação da Associação Brasileira de Ensino e Pesquisa em Serviço Social (ABEPSS) de 1996. Esses documentos em conjunto com todo o arcabouço teórico crítico construindo pela categoria nas décadas que se seguiram, constituem o Projeto ético-político da profissão vinculado a um projeto societário que vislumbra a ruptura com a ordem capitalista.

O Projeto Ético-Político expressa o compromisso do Serviço Social com os interesses da classe trabalhadora, se reconhecendo enquanto parte desta classe, a categoria compreende a sua natureza contraditória, mas a partir das mediações no cotidiano profissional, que são norteadas por seus princípios éticos e políticos vislumbra-se desenvolver uma práxis que possa romper com o conservadorismo que atravessa a natureza da profissão. Ao que tange tais princípios fundamentais, explicitamos:

I. Reconhecimento da liberdade como valor ético central e das demandas políticas a ela inerentes - autonomia, emancipação e plena expansão dos indivíduos sociais;

II. Defesa intransigente dos direitos humanos e recusa do arbítrio e do autoritarismo;

III. Ampliação e consolidação da cidadania, considerada tarefa primordial de toda a sociedade, com vistas a garantias dos direitos civis, sociais e políticos das classes trabalhadoras;

IV. Defesa do aprofundamento da democracia, enquanto socialização da participação politica e da riqueza socialmente produzida;

V. Posicionamento em favor equidade e justiça social, que assegure universalidade de acesso aos bens e serviços relativos aos programas e politicas sociais, bem como sua gestão democrática;

VI. Empenho na eliminação de todas as formas de preconceito, incentivando respeito à diversidade, à de grupos socialmente discriminados e a discussão das diferenças;

VII. Garantia do pluralismo, através do respeito às correntes profissionais democráticas e existentes e suas expressões teóricas e constante aprimoramento intelectual; 


\section{SILVA, G. P.}

O Estágio supervisionado em Serviço Social como estratégia de fortalecimento do Projeto éticopolítico

VIII. Opção por um projeto profissional vinculado a construção de uma nova ordem societária, sem dominação, exploração de classe, etnia e gênero;

IX. Articulação com os movimentos de outras categorias profissionais que partilhem dos princípios desse Código e a luta geral dos/as trabalhadores/as;

$\mathrm{X}$. Compromisso com a qualidade dos serviços prestados à população e com o aprimoramento intelectual na perspectiva de competência profissional;

XI. Exercício do Serviço Social sem ser discriminado, nem discriminar, por questão de inserção de classe social, gênero, etnia, religião, nacionalidade, orientação sexual, identidade de gênero, idade e condição física (CFESS. Código de Ética do Assistente Social, 1993).

Esses princípios expressam o impacto da "intenção de ruptura" no processo ressignificação do Serviço Social em sua totalidade, no que tange a formação em Serviço Social, como mencionamos acima, já no currículo de 1982 nota-se mudanças que demonstram esse redirecionamento, contudo são as Diretrizes curriculares da ABEPSS de 1996 que condensam todo o esforço da categoria em reorientar seu processo formativo, a partir de seus princípios fundamentais. Assim, em um cenário extremamente adverso de investida neoliberal com severas incidências nas relações de produção a partir da reestruturação produtiva e a instauração da contrarreforma do Estado que a categoria propõe um Projeto de Formação alinhado com seus princípios éticos e políticos, o qual pudesse possibilitar a apreensão da totalidade social nas dimensões de universalidade, particularidade e singularidade. No que refere aos princípios que fundamentam o projeto de formação profissional, explicitamos:

1. Flexibilidade de organização dos currículos plenos, expressa na possibilidade de definição de disciplinas e ou outros componentes curriculares - tais como oficinas, seminários temáticos, atividades complementares - como forma de favorecer a dinamicidade do currículo;

2. Rigoroso trato teórico, histórico e metodológico da realidade social e do Serviço Social, que possibilite a compreensão dos problemas e desafios com os quais o profissional se defronta no universo da produção; e reprodução da vida social.

3. Adoção de uma teoria social crítica que possibilite a apreensão da totalidade social em suas dimensões de universalidade, particularidade e singularidade;

4. Superação da fragmentação de conteúdos na organização curricular, evitando-se a dispersão e a pulverização de disciplinas e outros componentes curriculares; 


\section{SILVA, G. P.}

O Estágio supervisionado em Serviço Social como estratégia de fortalecimento do Projeto éticopolítico

5. Estabelecimento das dimensões investigativa e interventiva como princípios formativos e condição central da formação profissional, e da relação teoria e realidade;

6. Padrões de desempenho e qualidade idênticos para cursos diurnos e noturnos, com máximo de quatro horas/aulas diárias de atividades nestes últimos;

7. Caráter interdisciplinar nas várias dimensões do projeto de formação profissional;

8. Indissociabilidade nas dimensões de ensino, pesquisa e extensão;

9. Exercício do pluralismo como elemento próprio da natureza da vida acadêmica e profissional, impondo-se o necessário debate sobre as várias tendências teóricas, em luta pela direção social da formação profissional, que compõem a produção das ciências humanas e sociais;

10. Ética como princípio formativo perpassando a formação curricular

11. Indissociabilidade entre estágio e supervisão acadêmica e profissional (DIRETRIZES GERAIS PARA O CURSO DE SERVIÇO SOCIAL, 1996, p.67)

O Projeto de Formação exprimido pelas Diretrizes curriculares de 1996, conformam os núcleos de fundamentação da formação em Serviço Social. Quais sejam: núcleo de Fundamentos teórico-metodológicos da vida social; núcleo de Fundamentos da particularidade da formação sócio-histórica da sociedade brasileira e o núcleo de Fundamentos do trabalho profissional. A partir desses núcleos, a formação em Serviço Social é composta por um conjunto de conhecimentos indissociáveis que vão considerar as determinações históricas na sociedade contemporânea a fim traçar as estratégias necessárias para a materialização do fazer profissional alinhando com os princípios fundamentais da profissão.

É nessa direção que a atual proposta de estágio supervisionado em Serviço Social se alinha a esses princípios supracitados, que de forma indissociável, sustentam o legado crítico consolidado no bojo do Serviço Social nas últimas décadas, contudo isso não ocorre sem tensionamentos, seja pelas tensões próprias da natureza contraditória da profissão, seja pelas contradições vinculadas ao âmbito político, econômico, social e cultural na sociedade burguesa, em tempos de neoliberalismo.

No que se refere as implicações do neoliberalismo no Brasil, Duriguetto (2007, p, 171) destaca que, é no curso da década 1990 que as primeiras ressonâncias do receituário neoliberal passaram a incidir na realidade nacional, sobretudo, a partir da implementação das medidas de ajuste estrutural preconizadas 
pelo Consenso de Washington, em correspondência com o aprofundamento dos processos de globalização. A autora ainda pondera que, com o governo Collor (fevereiro de 1990 a setembro de 1992) operou-se uma drástica redução da agenda pública, de acordo com a agenda neoliberal. Sinteticamente,

[...] A nova agenda política de ajuste passou a ser dominada por temas como refluxo do Estado e primazia do mercado através das políticas de abertura comercial e financeira ao capital internacional, desregulamentação e privatização, redução dos fundos públicos para o financiamento das políticas sociais, enfim, uma agenda que só podia ser conduzida contra as conquistas de 1988 (DURIGUETTO, 2007, p.171).

Essas alterações supracitadas, impostas pelo neoliberalismo no contexto brasileiro, impactam em todos os âmbitos da vida. Verifica-se nesse processo, sobretudo, os efeitos da reestruturação produtiva evidenciada pela flexibilização das relações de trabalho, expressa pela maximização das privatizações e terceirizações, as quais refletem na precarização das condições de trabalho em concomitante enxugamento de postos de trabalhado, o que implicou um crescimento exorbitante do exército industrial de reserva. Em suma,

\begin{abstract}
A flexibilização das normas contratuais (ou seja, das regras que regem a contratação, o uso, a remuneração e a dispensa da força de trabalho) expressa, também, a segmentação da organização sócio-política (representação e negociação) em seu interior, em que milhares de trabalhadores são postos numa situação de excludência no que concerne a medidas que favoreçam a formulação de direitos relacionados às suas necessidades e interesses [...] Assim, as mudanças no mundo do trabalho vêm conformando sociabilidades, formas de organização e representação política na direção da fragmentação, despolitização e multiplicação de demandas de grupos de interesses corporativamente posicionados, ou seja, cada vez mais fechados em sim mesmos (DURIGUETTO, 2007, p. 173-4).
\end{abstract}

A propagação da égide neoliberal assentou-se na disseminação da ideia de "socialização" dos efeitos nocivos da "crise", cujo objetivo foi ganhar consentimento dos/as trabalhadores/as acerca de novos valores políticos, sociais e éticos, que legitimem as mudanças requeridas pelo processo de reestruturação produtiva e o desmonte de mecanismos de proteção social Mota (1995, p. 164 apud Duriguetto, 2007, p. 172). 
Essas alterações implicadas pelo avanço do neoliberalismo no Brasil incidem em todos os âmbitos da profissão, no que tange a formação profissional a contrarreforma da Educação impõem desafios concretos ao Projeto de Formação presente nas Diretrizes Curriculares de 1996 e consequentemente na proposta de Estágio Supervisionado presente neste. Ne direção destacamos o processo de flexibilização da formação via a modalidade de graduação à distância/EaDs, aligeiramento na formação, expansão desenfreada de universidades privadas, com apoio dos programas de financiamento do governo, e o processo de sucateamento das universidades públicas, a destacar, por exemplo, a insuficiência de infraestrutura via REUNI.

Ao considerarmos o exercício profissional, o avanço da contrarreforma do Estado ao implicar um processo acelerado das privatizações, via terceirizações bem como da refilantropização com o crescimento das Organizações Sociais, por exemplo, tem configurado espaços sócio ocupacionais para os/as Assistentes Sociais marcados pela precarização e fragilização dos vínculos trabalhistas.

É importante salientarmos que, tal cenário contextualizado acima tem se acirrado nos últimos anos, contudo no sentido de adensar a direção ético e política em vigor no bojo do Serviço Social constatamos ações concretas que objetivam instrumentalizar e garantir a manutenção e fortalecimento do PEP. No que tange a proposta de Estágio Supervisionado, para além das DC-1996 verificamos outros instrumentos sistematizados pelo conjunto da categoria os quais destacamos, Resolução 493/2006 que dispõe sobre as condições éticas e técnicas do exercício profissional; Resolução 533/2008 que regulamenta a supervisão direta de Estágio Supervisionado em Serviço Social; Política Nacional de Estágio da ABEPSS/2009; Cartilha "Meia Formação não garante um Direito" elaborada pelo Conjunto CFESS/CRESS; Projeto ABEPSS Itinerante, Campanha da ABEPSS "Sou Assistente Social e supervisiono estágio".

Essas são algumas das sistematizações da categoria que buscam fomentar, qualificar, disseminar e fortalecer o significado do Estágio Supervisionado no processo de formação e exercício profissional, como uma estratégia concreta de fortalecimento do nosso Projeto ético-político. Ressaltamos aqui a necessidade de 
apropriação de tais documentos e de todo arcabouço teórico-metodológico que condensa todo o esforço das/os profissionais e estudantes que buscam garantir uma formação de qualidade atrelada à concepção de práxis a partir da indissociabilidade entre teoria e prática.

A fim de elucidar o conteúdo dessas sistematizações, na próxima seção recorreremos a algumas delas na tentativa de refletir e considerar os desafios impostos ao nosso Projeto de Formação e a proposta de Estágio Supervisionado inscrita no mesmo. Importante salientarmos que, parte significativa das reflexões que faremos a seguir foram possíveis pela experiência profissional na docência na graduação, mas especificamente na condição de supervisora acadêmica, e posterior como responsável de uma disciplina que tinha como objetivo aproximar as/os discentes a proposta de Estágio Supervisionado em Serviço Social, intitulada Introdução ao Estágio em Serviço Social.

\section{O ESTÁGIO SUPERVISIONADO EM SERVIÇO SOCIAL COMO ESTRATÉGIA DE FORTALECIMENTO DO PROJETO ÉTICO-POLÍTICO}

Como já viemos demonstrando, nas últimas quatro décadas a categoria profissional se empenhou em combater o conservadorismo imanente a sua existência. Tal processo como destacamos traduz o compromisso ético e político do Serviço Social com os interesses da classe trabalhadora se reconhecendo como parte desta, ou seja, não estando alheio as agruras impostas pelo capital na figura da dominação burguesa. Parte significativa desse salto qualitativo e organizativo da categoria tem como respaldo extremamente importante a existência de parâmetros jurídico-políticos para garantir e resguardar a posição crítica hegemônica que conforma o nosso Projeto ético-político.

Considerando a importância desses parâmetros jurídico-políticos para a garantia do legado crítico do Serviço Social, ponderamos a necessidade de permanente conhecimento e qualificação de todo aparato fomentado pelo conjunto da categoria. Em se tratando especificamente do Estágio Supervisionado nos referimos ao conhecimento e reflexão constante do nosso Projeto de Formação 


\title{
SILVA, G. P.
}

O Estágio supervisionado em Serviço Social como estratégia de fortalecimento do Projeto éticopolítico

inscrito nas Diretrizes Curriculares da ABEPSS, é este acesso que nos dá subsídios para defender no cotidiano profissional nossa concepção de Educação que confronta o projeto neoliberal vigente.

Nossa experiência com a proposta de Estágio Supervisionado em Serviço Social presente no atual Projeto de Formação, no âmbito da docência, foi extremamente profícua em um esforço de fortalecer esta proposta na relação com discentes no primeiro período de estágio e no preparo de discentes que iriam ingressar no estágio. Ambas as experiências nos possibilitou pensar em estratégias concretas no enfrentamento a fragmentação do processo de ensino e aprendizagem, através da sistematização de um plano de ensino que possibilitou espaços de interação entre docentes de Serviço Social, Assistentes Sociais na condição de supervisoras/es ou não, discentes na condição de estagiárias/os ou não.

Considerando que as questões vinculadas ao processo de estágio dizem respeito às próprias incidências colocadas para formação e para o exercício profissional, tal como Caputi (2016, p.390) sintetiza:

\begin{abstract}
O estágio supervisionado em Serviço Social e, com ele, o processo de supervisão, acompanha o movimento sócio histórico, teórico-metodológico e as condições éticas e políticas que envolvem a profissão, desde os seus primórdios na realidade brasileira. $\mathrm{O}$ debate sobre a supervisão de estágio no Serviço Social é efervescente nos tempos hodiernos, sobretudo considerando: a maturidade intelectual da categoria; a perspectiva de indissociabilidade entre formação e exercício profissional; as lutas travadas na defesa da educação de qualidade e a resistência com relação à precarização da educação superior e suas ressonâncias no Serviço Social, sobretudo, no que diz respeito à modalidade de Ensino à Distância para graduação; preocupação diante da ofensiva neoliberal; e enfim, o compromisso com a consolidação do Projeto Ético-Político da Profissão, elementos pelos quais, foi delineada em 2008, pelo CFESS, a Resolução n.533, responsável pela regulamentação da supervisão direta de estágio, e, em 2010, a Política Nacional de Estágio em Serviço Social/PNE, ABEPSS.
\end{abstract}

Foi a partir dessa perspectiva que em nossa experiência metodologicamente, partimos do estudo atento às Diretrizes Curriculares da ABEPSS a fim de explicitar e conceituar o Projeto de Formação ali presente. Qual seja:

[...] as Diretrizes Curriculares propostas pela ABEPSS implicam numa capacitação teórico-metodológica, ético-política e técnico-operativa para a apreensão teórico-crítica do processo histórico como totalidade; da apreensão das particularidades da constituição e desenvolvimento do 
capitalismo e do Serviço Social na realidade brasileira; da apreensão das demandas e do significado social da profissão; e o desvelamento das possibilidades de ações contidas na realidade e no exercício profissional que cumpram as competências e atribuições legais. (ABEPSS, 1996, p.7).

Reiteramos o significado político dessa sistematização da categoria em defesa de uma formação coerente com nosso Projeto ético-político, objetivamos com isso incidir sobre os efeitos das Diretrizes Curriculares aprovadas pelo Ministério da Educação em 2002 que não contempla na totalidade o conteúdo presente no documento da categoria, ou seja, o deturpa em um cenário marcado por desafios vinculados

[....] a precarização do ensino e do trabalho docente nas universidades públicas; e, o concomitante crescimento das instituições privadas de ensino, inclusive na modalidade de Ensino a Distância (EAD), que têm como desdobramento a ampla formação de assistentes sociais com currículos flexíveis e frágeis na apreensão da teoria social crítica e a dificuldade de consolidar, na formação profissional dos assistentes sociais, o tripé ensino, pesquisa e extensão (AQUINO, I. et al. 2016 p. 403).

Retomar esses desafios nos possibilitou mensurar o quadro conjuntural que tem impactado a formação e o exercício profissional. Mas, sobretudo, apresentar os esforços coletivos da categoria no enfrentamento ao cenário de agudizamento dos efeitos deletérios do capital sob a hegemonia neoliberal, tal como supracitado. No que tange aos esforços do conjunto categoria sobre a formação com a centralidade no Estágio Supervisionado, avançamos nossas aproximações com o estudo e reflexão das Resoluções do conjunto CFESS, mais especificamente resolução 493/2006 e 533/2008.

A resolução 493/2006 reivindica e normatiza as condições éticas e técnicas do exercício profissional da/o Assistente Social, qualificando o que já estava previsto na Lei de Regulamentação da profissão 8662/93 e no Código de Ética vigente, ao estabelecer que a instituição de atuação deverá assegurar espaço físico adequado, sigilo profissional, equipamentos necessários, disponibilidade do/a supervisor/a de campo para acompanhamento presencial da atividade de aprendizagem, dentre outros requisitos básicos, nos termos da Resolução (CFESS, 2013, p.22). 


\section{SILVA, G. P.}

O Estágio supervisionado em Serviço Social como estratégia de fortalecimento do Projeto éticopolítico

A fim de regulamentar a Supervisão Direta de Estágio é aprovada a resolução 533/2008 que normativa os elementos necessários para a realização do processo de Supervisão.

[...] em 2008 a Resolução no533 é aprovada no 38ํㅡㄹ Encontro Nacional, considerando todo o acúmulo obtido no processo histórico de sua formulação, a necessária conformidade com as normativas da profissão (Código de Ética, Lei 8.662/1993 e Diretrizes Curriculares da ABEPSS), o cumprimento dos dispositivos legais definidos pela Lei Federal, buscando alcançar a garantia da aprendizagem e do exercício profissional com qualidade e orientado pelo Projeto ético-político (CFESS, 2013, p.22).

A regulamentação da Supervisão Direta de Estágio objetivou resguardar todo o processo de estágio supervisionado na articulação entre supervisoras/es acadêmicas/os, supervisoras/es campos e estagiárias/os, bem como, na abertura de campos através da interlocução de Unidade de Formação, Espaço Sócio Ocupacional e CRESS. Considerou as formas especificas de Estágio curricular obrigatório e Estágio não obrigatório, mas reiterou a necessidade de ambos terem que garantir os pré-requisitos previstos na resolução, isto é; realizar o estágio apenas com o acompanhamento de supervisor/a de campo e acadêmico, elaborar plano de estágio, sistematizar cronograma de atividades, refletir e pensar estratégias para enfrentar questões relacionadas ao estágio, atestar/reconhecer as horas de estágio realizadas pela/o estagiária/o, bem como emitir avaliação e nota, quando necessário.

Na contramão do conteúdo da lei 11.788/2008 que prevê até 10 estagiárias/os por supervisor/a, a Resolução 533/2008 orienta como limite máximo de estagiária/o por supervisor/a não deverá exceder 1(um/a) estagiário/a para cada 10 (dez ) horas semanais de trabalho do/a profissional. Ainda reiterou a supervisão como uma atribuição privativa do/a Assistente Social, que deve ser desempenhada como parte da atividade profissional nos diversos espaços sócio ocupacionais tendo como prérequisito os parâmetros normatizados pela resolução.

Ambas as resoluções tem caráter normativo e preveem um conjunto de ações para qualificar seus pré-requisitos e materializar no cotidiano, seja via tensionamento da dimensão fiscalizadora exercida pelos CRESSs de cada localidade, mas, 


\section{SILVA, G. P.}

O Estágio supervisionado em Serviço Social como estratégia de fortalecimento do Projeto éticopolítico

sobretudo, pela dimensão político-pedagógica ao respaldar as/os Assistentes Sociais nos diversos processos de disputas nos espaços sócio ocupacionais.

Concomitante a apreensão desses documentos, nos detemos ao conhecimento da Política Nacional de Estágio da ABEPSS/2009, que reflete um significativo salto qualitativo dos esforços coletivo da categoria. Mesmo não tendo força de lei tem a legitimidade do debate coletivo no âmbito da ABEPSS como entidade acadêmica, e fornece parâmetros nacionais para a construção das políticas de estágio em cada unidade acadêmica (CFESS, 2013, p. 14).

A PNE aglutinou reflexões importantes vinculadas a dinâmica da realidade contemporânea, e como as mudanças que ocorrem incidem no cotidiano profissional, requisitando a permanente ação da categoria na manutenção de seu legado crítico frente a um cenário de restrição de direitos sociais, perdas democráticas e notório avanço do conservadorismo reacionário. Nessa direção a PNE reafirma o significado do estágio, pois este

[...] se constitui num instrumento fundamental na formação da análise crítica e da capacidade interventiva, propositiva e investigativa do/a estudante, que precisa apreender os elementos concretos que constituem a realidade social capitalista e suas contradições, de modo a intervir, posteriormente como profissional, nas diferentes expressões da questão social, que vem agravando diante do movimento mais recente de colapso mundial da economia, em sua fase financeira, e de desregulamentação do trabalho e dos direitos sociais (PNE, 2011, p. 11).

Refletir o conteúdo dessas formulações se apresentou para nós como uma possibilidade de apreender e fortalecer no Projeto de Formação, considerando o significado da proposta de Estágio Supervisionado como momento fundamental para a consolidação da relação entre teoria e prática presente nas Diretrizes Curriculares de 1996. Em síntese:

A PNE afirma o estágio como possibilidade concreta de materialização da lógica curricular, na perspectiva das diretrizes curriculares da ABEPSS de 1996, assim como consoante aos princípios do Código de Ética dos/as assistentes sociais de 1993. Numa leitura atenta e crítica da realidade, a PNE enfatiza, ainda, que o estágio no Serviço Social deve também se nortear por princípios que são preservadores desta lógica, quais sejam, indissociabilidade entre as dimensões teórico-metodológicas, ético-políticas e técnico-operativas; articulação entre formação e exercício profissional; indissociabilidade entre estágio, supervisão acadêmica e de campo; 
articulação entre universidade e sociedade; unidade entre teoria e prática; articulação entre ensino, pesquisa e extensão (PNE, 2009, p.12-14 apud CFESS, 2013, p.15)

Ao considerar o conjunto desses documentos Lewgoy (2013, p. 71) enfatiza que eles avalizam a direção de enfrentamento recomendado pela organização política da categoria profissional frente "à precarização do ensino e [...] à lógica formativa de adestramento presentes no cotidiano dos cursos e do mercado do trabalho profissional" (SANTOS; ABREU, 2012, p. 81 apud Lewgoy, 2013, p.71).

Como parte do processo de apreensão da proposta de Estágio supervisionado em Serviço Social propomos um espaço que garantiu a interação de discentes que estavam cursando a disciplina de Introdução ao Estágio e de discentes que estavam no primeiro período de estágio. Nesse espaço contamos com a participação de uma supervisora de campo, uma supervisora acadêmica e uma estagiária. Foi um espaço pautado na articulação de conteúdo teórico-metodológico, ético-político e técnico-operativo, com ênfase nos processos que perpassam o cotidiano profissional.

As/os discentes tiveram a oportunidade de aproximar concretamente as experiências particulares das três instâncias que de forma articulada correspondem ao processo de estágio supervisionado. Isto é, ter acesso a socialização do cotidiano de uma Assistente Social inserida em espaço sócio ocupacional marcado por questões vinculados ao cenário econômico, político, social e cultural do país, que tem que lidar com questões especificas ao que Ihe é requisitado pela instituição, e que sente no dia-a-dia os tensionamentos impostos pela configuração de uma autonomia relativa que marca a intervenção profissional.

A contribuição da supervisora acadêmica, também foi muito elucidativa ao compartilhar os esforços do Departamento do curso em conformar uma Política de Estágio a partir do que está previsto nas DC e na PNE. Apresentou as lacunas que precisam ser sanadas para garantir a materialização das diretrizes para o estágio supervisionado.

O relato da estagiária foi extremamente proveitoso, pois ao articular as socializações das supervisoras, pudemos constatar concretamente os desafios, 
mas, sobretudo, as possibilidades que o estágio e a supervisão de estágio proporciona as/os envolvidos, bem como a sociedade com realização de ações que fomentam o acesso a serviços, a direitos, a informação, ou seja, potencializa o caráter social da concepção de Educação presente no Projeto de Formação em Serviço Social, como explicitamos ao longo desse artigo.

\section{CONSIDERAÇÕES FINAIS}

Objetivamos nesse artigo compartilhar nossas aproximações ao Projeto de Formação vigente no bojo do Serviço Social, de modo que pudéssemos apresentar nossas apreensões sobre o Estágio e o processo de Supervisão proposto pelo conjunto da categoria.

Pudemos compreender que a proposta do Estágio bem como da Supervisão elucida o empenho do Serviço Social em qualificar uma formação crítica, que possibilita apreender as contradições imposta pela sociedade classes, tais contradições devem identificadas e escancaradas no processo de formação e no exercício profissional.

Consideramos que no processo de estágio essa possibilidade é potencializada ao conceber a relação dialética entre teoria e prática, enquanto unidade no diverso, e proporciona uma interlocução entre profissionais no âmbito da formação e exercício e estudantes em formação.

Por fim, verificamos que este empenho coletivo da categoria em qualificar o Estágio no âmbito da formação e do exercício profissional, tem como objetivo fortalecer o nosso Projeto ético-político que tem como horizonte estratégico a ruptura com as bases fundantes que sustentam a sociedade capitalista.

\section{REFERÊNCIAS}

ABEPSS. Associação Brasileiro de Ensino e Pesquisa. Diretrizes gerais para o curso de Serviço Social: com base no currículo mínimo aprovado em assembleia geral extraordinária de 8 de novembro de 1996. Rio de Janeiro: ABEPSS, 1996. 


\section{SILVA, G. P.}

O Estágio supervisionado em Serviço Social como estratégia de fortalecimento do Projeto éticopolítico

Política Nacional de Estágio da Associação Brasileira de Ensino e Pesquisa em Serviço Social, 2010. Disponível em: http://www.cfess.org.br/arquivos/pneabepss_maio2010_corrigida.pdf

AQUINO, I. et al. Estágio supervisionado em Serviço Social: desfazendo nós e construindo alternativas. Relatório ABEPSS Itinerante 2014. Temporalis, Brasília, 2016. Disponível em: http://periodicos.ufes.br/temporalis/article/view/13351/10114

CAPUTI, Lesliane. Supervisão de estágio em Serviço Social: significâncias e significados. In: Katálysis, Revista/ PPGSS-UFSC, v. 19, n. 3. Florianópolis, 2016. Disponível em: http://www.scielo.br/pdf/rk/v19n3/1414-4980-rk-19-03-00389.pdf

CFESS. Código de Ética Profissional da/o Assistente Social. Brasília: CFESS, 1993. Disponível em: http://www.cfess.org.br/arquivos/CEP_CFESS-SITE.pdf

. Cartilha Estágio Supervisionado: Meia formação não garante um direito.

Brasília: CFESS, 2013. Disponível em:

http://www.cfess.org.br/arquivos/BROCHURACFESS_ESTAGIO-

SUPERVISIONADO.pdf

DURIGUETTO, M.L. Sociedade Civil e democracia: um debate necessário. São Paulo: Cortez, 2007.

NETTO, J.P. Ditadura e Serviço Social: Uma análise do Serviço Social no Brasil pós-64. 16 ed. São Paulo: Cortez, 2011.

LEWGOY, I.M.B. O estágio supervisionado em serviço social: desafios para articulação entre formação e exercício profissional. In: Temporalis, Revista. Brasília, 2013. Disponível em: http://periodicos.ufes.br/temporalis/article/view/4850/4143 